\title{
LEOPARD FROG PREDATION ON EMERGING ADULTS OF COLONIZING VARIEGATED MEADOWHAWK DRAGONFLIES
}

\section{David J. Larson \\ Box 56 \\ Maple Creek, SK SON 1NO \\ dmlarson@sasktel.net}

The early spring of 2016 was very dry in southwestern Saskatchewan.

The soil was dry the previous fall and very little snow fell over the winter. Spring melt occurred with no runoff so vernal ponds were empty and water levels in dugouts and dams were low. At a period with so much concern about climate change, one could not help but wonder if this drought presaged future dry conditions.

At any rate, it is never a bad idea to try to improve water security. The dry soil meant that heavy equipment could operate without doing too much damage. We hired a track-hoe to come in late April to dig a dugout and make two dams. These observations relate to the larger of the dams, which we called Cactus Flats Dam in recognition of the habitat that was destroyed in its construction. It is located on the north slope of the Cypress Hills (SW 280926 W3), about $14 \mathrm{~km} \mathrm{~S}$ of Maple Creek.

The dam was built at the confluence of two small coulees that cut through Bearpaw age bedrock consisting mainly of clays and shales with lenses of sand and gravel. The coulee bottom was an alluvial pan of white clay with sparse vegetation of mainly western wheat grass, cacti and sagebush. On completion, the water depth could potentially average 5 to $6 \mathrm{~m}$ in a pond about 75 by $50 \mathrm{~m}$, and flood up the side walls of the coulee into a mixed grassland community of gramma, needle grass,

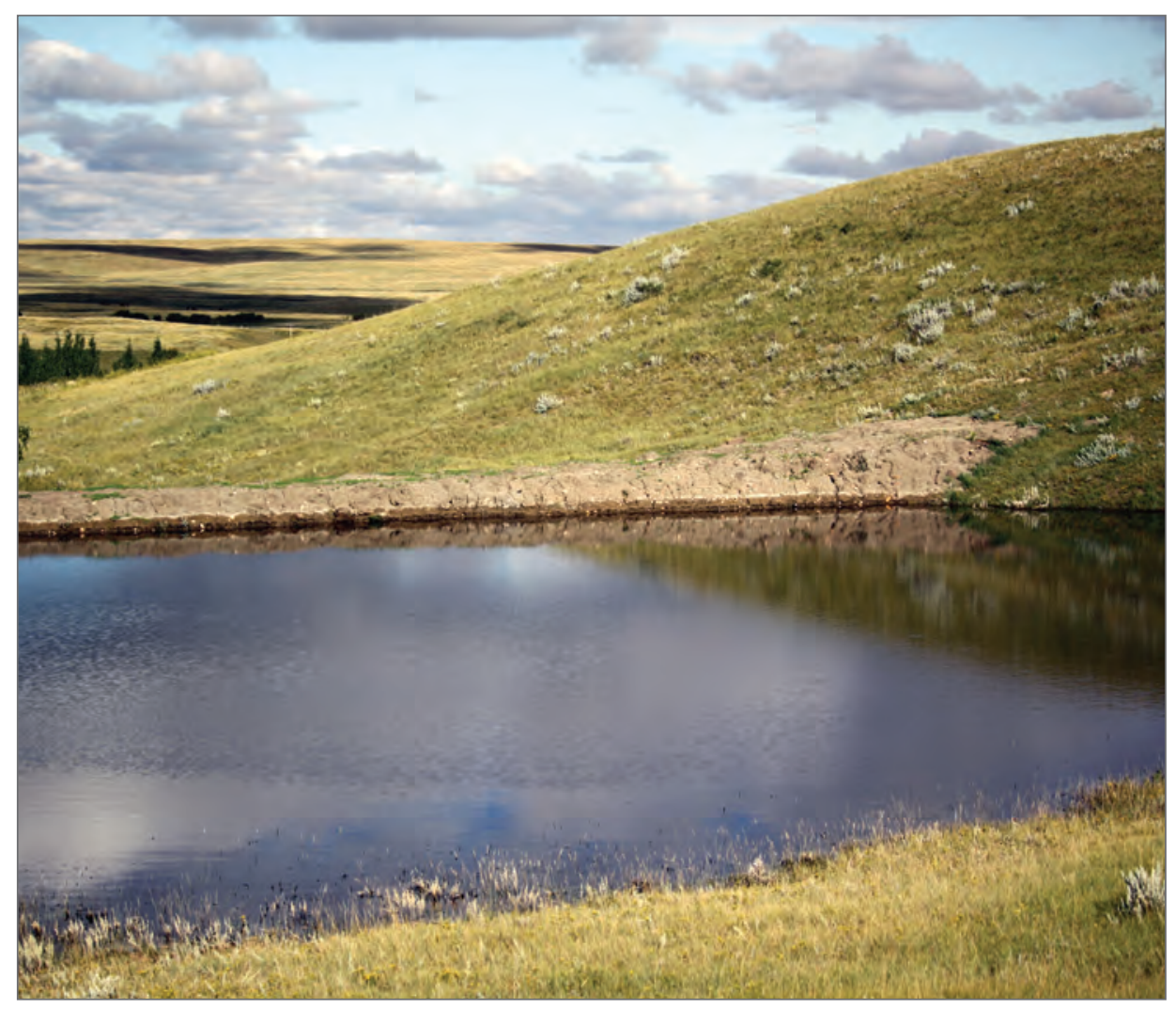

FIGURE 1. Cactus Flats Dam with water level near capacity. Dragonfly and frog observations were made along the shorelines where the grass was flooded. Photo credit: D. Larson

and prairie muhly on sandy-clay soil. The term potentially is used because our feeling was that it would take several years of accumulated runoff to reach the outflow culvert level, if ever.

The weather changed - there was a little rain and snow in late April, just during the last phases of construction, that put more than $1 \mathrm{~m}$ of water into the basin of the dam. Over the next several weeks, heavy rainfalls (e.g. more than $60 \mathrm{~mm}$ on May 9 and 10) added more run-off and by mid-July the dam was close to full. Most of the pond was 4 to $5 \mathrm{~m}$ deep but there were shallow margins where the sparse grasses had been flooded to give an emergent zone of drowning arid land plants along the shoreline (Fig. 1).
I took great pleasure in visiting the dam each day to watch the water level rise. Immediately on holding water, new life appeared. On the first night of there being water, an invasion of larger water bugs, most notably backswimmers (Notonecta), and water beetles (Acilius,

Graphoderus and Rhantus) occurred. Smaller water boatmen (Corixidae) and water beetles (Dytiscidae, Gyrinidae, Hydrophilidae) quickly followed. Shore flies, small ground beetles (Bembidion), rove beetles, variegated mud-loving beetles and shore bugs populated the mud at the water's edge. Chironomid flies and mayflies (Callibaetis sp.) swarmed along the waters edge and oviposited over the water. Microcrustaceans became apparent, 
first shoreline swarms of copepods then later of daphnia. Changing water color indicated various algal blooms, filamentous algae formed a mat along the shorelines and duckweed colonized protected embayments.

Dragonflies appeared, most abundant were small blue damselflies that perched on emergent grass stems along the shoreline or that paired up in tandem sets in mating and egg laying. Larger dragonflies were less abundant but were more conspicuous, especially the spectacularly patterned Twelvespotted Skimmer (Libelulla pulchella).

Amphibians also appeared. A few Striped Chorus Frogs (Pseudacris triseriata) called from amongst a dense patch of flooded grasses but this lasted only a few days and no eggs or tadpoles were found. Occasionally in the deeper water some larger creatures rolled or thrust their forebody up out of the surface. These were probably Tiger Salamanders (Ambystoma tigrinum) as they occur in a neighbouring dam. Northern Leopard Frogs (Rana pipiens) were very common from July into early October when there was a heavy snowfall. However, a few reappeared later and the last was seen in mid-November.

Daily observations of this vein were made over the summer. On August 16, there was a teneral (a newly moulted insect in which the cuticle is soft and usually pale) female specimen of a small dragonfly - a meadowhawk (Sympetrum) species. This specimen seemed most unusual as species of meadowhawk are abundant in local ponds but generally have a one-year life cycle with eggs laid one summer emerging as adults the following summer. This dam was not present the previous summer, the dragonfly had to have been laid as an egg after May and its larval development completed by August 16. Most local meadowhawk species do not occur as adults in the spring - they are summer to fall species and a rough rule of thumb is that any small pond dragonfly seen in spring and early summer is a whiteface (Leucorrhinia species) and in summer and fall is a meadowhawk species. I resolved to return the next day to see if I could find a male, preferably one with sufficiently hard cuticle that it would be suitable for identification and preservation as a voucher specimen.

On August 17, the shoreline of the dam had numerous exuviae (the cast cuticle left behind when an insect moults, Fig. 2) and some newly emerged dragonflies. They had probably emerged overnight for at 09:00 h some specimens were leaving the shoreline area in the weak fluttering first flight of a newly emerged dragonfly. I checked out a number of specimens near the water's edge to find one suitable to collect but all were too teneral. I would have to find a specimen that had flown from the pond and had a more hardened cuticle. However, what I did notice was several dragonflies had no abdomens they had been decaudated (Figs. $3,4,5)$. They were still alive and clinging to grass stalks but were immobile. If prodded to move they were unsteady and could not fly. Also, leopard frogs were abundant and I wondered if these were the culprits that had injured the dragonflies.

In order to get a better measure on what was observed, a simple count was conducted that consisted of walking a line $1 \mathrm{~m}$ back from the edge of the pond and at each pace (a little less than $1 \mathrm{~m}$ but a close approximation) stopping and counting frogs, and dragonflies (as exuviae; tenerals; tenerals with no

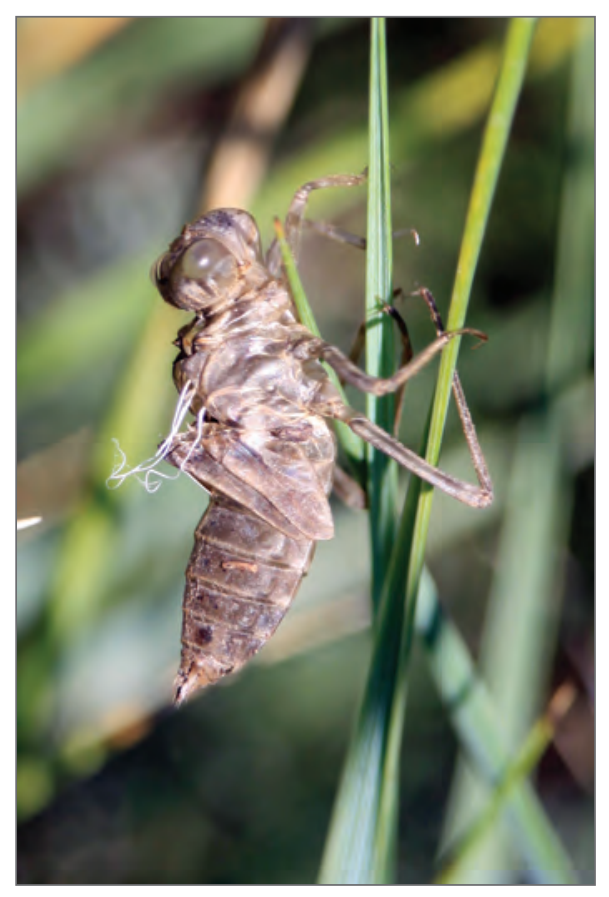

FIGURE 2. Exuvium, shed larval cuticle, of the Variegated Meadowhawk dragonfly. Photo credit: D. Larson

abdomen; and sets of dragonfly wings (presumably a dragonfly eaten by some predator that left the wings)). The frogs counted were those that flushed when a step was made; the various dragonfly stages were those seen within the area in front of me that could be carefully searched without moving my feet, roughly $1 \mathrm{~m}^{2}$. Two 25-pace transects were walked but dragonflies were counted on only one. The second transect had such dense grass that exuviae could only be found by laborious searching. The counts were made between 10:00 and 12:00 h, and the day was sunny and warm with a light SW wind. The results are given in Table 1. On a return visit the following day (August 18), no new exuviae or teneral specimens were observed so the counts were not repeated.

The results of the survey indicate that there were more exuviae than dragonflies. The exuviae were not present (at least not noticed) on the previous morning (August 16) and they probably represent overnight 

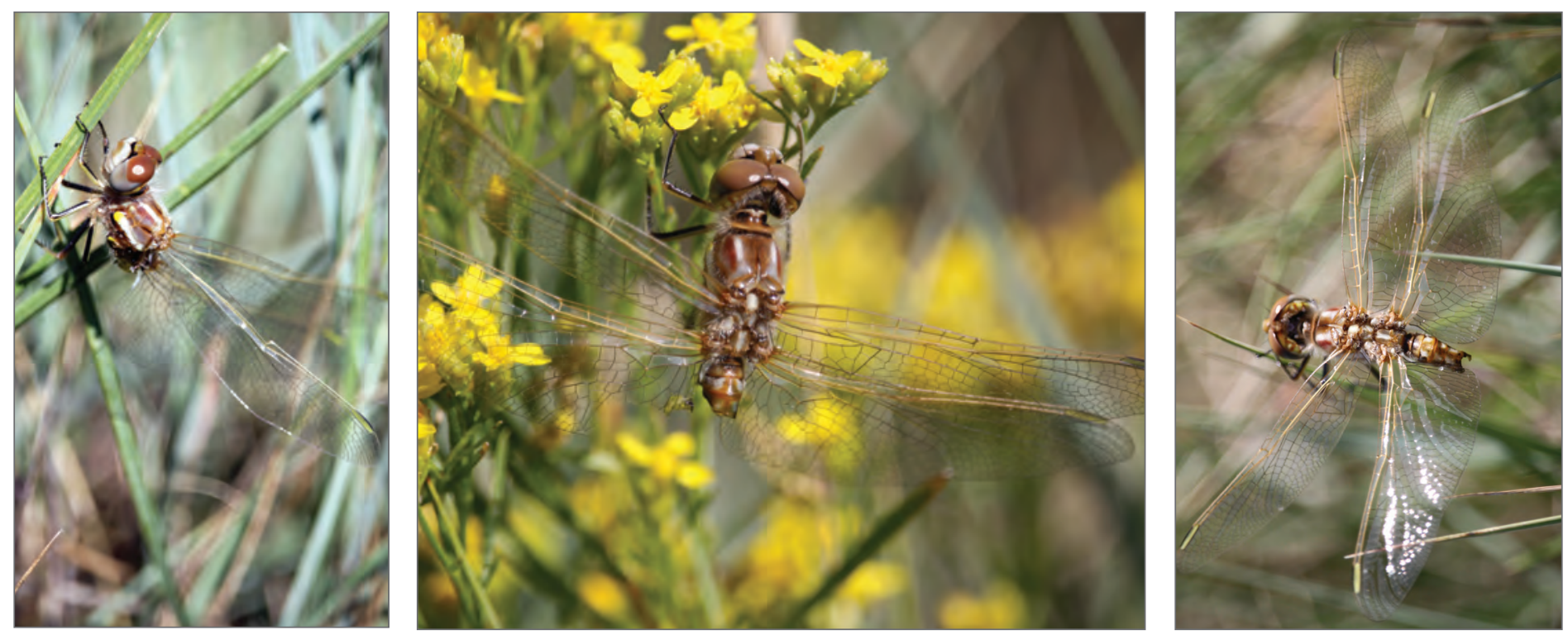

FIGURES 3, 4, 5. Variegated Meadowhawk, teneral adults that had been decaudated (abdomens removed). Photo credit: D. Larson

emergence (August 16/17) with most : new adults flying away from the pond before the count was made in the morning. This was supported by observation of teneral but airworthy dragonflies both on vegetation and flying at distances of several hundred metres or more downwind from the pond. A voucher specimen was collected from among these. This corresponds to the observation of Hutchings and Halstead that dragonflies tend to emerge under the cover of darkness as it reduces the likelihood of predation. ${ }^{1}$ The newly emerged dragonflies must have dispersed rather quickly from the pond edge into the surrounding grasslands. The population in the dam apparently emerged in one synchronized peak over the night of August 16/17 and most specimens had left the pond margin by noon of August 17. During this emergence period, the population suffered a predation mortality of at least 16 per cent based on remains (wings) and injured (decaudate) specimens. If entire insects (either or both nymphs and adults) were consumed, this mortality estimate would be too low.

I accuse the leopard frogs (Fig. 6) as being the predator. This is based on not seeing any other potential predator. Two Lesser Yellowlegs and one Spotted Sandpiper were present on the morning of August 17 , but their foraging was along barren, muddy shorelines and not in the grass. A sparrow (unidentified, possibly a Savannah Sparrow) was seen in shoreline grass on the other side of the pond but not in the survey area, although there were several hours of daylight in the morning before the survey was made during which time a bird could have dined on dragonflies. There is the question as to why a predator would be satisfied with snipping the abdomen off a dragonfly. Once the abdomen was taken, the dragonfly would be helpless, easy prey and the thorax with its large flight muscles would be the most nutritious part of the insect. If a frog was acting as an ambush predator, the act of snapping the abdomen off a moving, teneral dragonfly would traumatize the dragonfly and probably render it immobile, at which point the frog may not recognize the inert body as prey and not continue the attack.

The dragonfly was identified as Variegated Meadowhawk (Sympetrum corruptum (Hagen)) (Fig. 7). This species has a wide range in North America extending from Mexico north into the boreal zone of the Prairie provinces, although Hutchings and Halstead regard it as a fringe species in the western boreal forest. ${ }^{1,2}$ The life history of Variegated Meadowhawks in the Canadian prairies is not well known. Walker \& Corbet report that there tend to be two seasonal peaks in adult abundance, one from June to

TABLE 1. Number of leopard frogs and Variegated Meadowhawk dragonflies counted in each transect, August 17, 2016, 10:00 to 12:00 h: total numbers (number per pace in brackets). Per cent (\%) mortality is the ratio of the number of dragonflies for which there is evidence of death (decaudate, or only wings remaining) to the number of emerging dragonflies (exuviae only counted). $\mathrm{nr}=\mathrm{no}$ record.

\begin{tabular}{|l|l|l|l|l|l|l|l|}
\hline \multicolumn{1}{|c|}{ \# PRANSECT } & \multicolumn{1}{|c|}{ FROGS } & \multicolumn{1}{c|}{ EXUVIAE } & \multicolumn{1}{c|}{ TENERALS } & \multicolumn{1}{c|}{ DECAUDATED } & \multicolumn{1}{c|}{ WINGS ONLY } & \multicolumn{1}{c|}{ \% MORTALITY } \\
\hline 1 & 25 & $13(0.52)$ & $80(3.2)$ & $4(0.16)$ & $8(0.32)$ & $5(0.20)$ & 16.25 \\
\hline 2 & 25 & $19(0.76)$ & $\mathrm{nr}$ & $\mathrm{nr}$ & $\mathrm{nr}$ & $\mathrm{nr}$ & $\mathrm{nr}$ \\
\hline
\end{tabular}


early July and a second in August and September. ${ }^{3}$ However, this is known to be a highly migratory species that breeds more or less continuously over the year in the southwestern United States and disperses out of these breeding areas as warm weather advances in the spring. It is possible that the early population peak on the Prairies represents migrants from the south rather than individuals that overwintered in the north as nymphs. This was suggested by Walker \& Corbet and supported by Paulson who states adult specimens, especially males, are found in the spring from British Columbia to Manitoba before any sign of emergence. ${ }^{2,3}$ The species breeds in shallow open or marshy lakes and ponds, often alkaline, and also in temporary or newly formed water bodies. ${ }^{2,3}$ My observations fit the pattern of migrant adults from the south ovipositing in Cactus Flats dam in May or June as it was filling with water, and the resulting nymphs completing growth and emerging as adults in later August.
Thus, this species was able to colonize new habitat and complete a generation taking advantage of the flush of productivity in a newly formed habitat with no competition or significant aquatic predation. However, this strategy was somewhat foiled when emerging dragonflies encountered predation as they crawled into a shoreline aggregation of leopard frogs.

In a more rigorously designed survey of leopard frogs in Manitoba, Hamel \& Grantham found an average density of 0.29 frogs per $\mathrm{m}^{2}$ in a pothole wetland area. ${ }^{4}$ The density at Cactus Flats Dam was higher but the count was made along the shoreline where frogs were concentrated. The quarter section in which the dam occurs has several other dams, dugouts and a seasonal stream along which frogs are regularly observed. They are often found in grasslands away from water but at low densities and a survey of frog density in the grasslands would probably indicate only that they were present. Corbet states "frogs

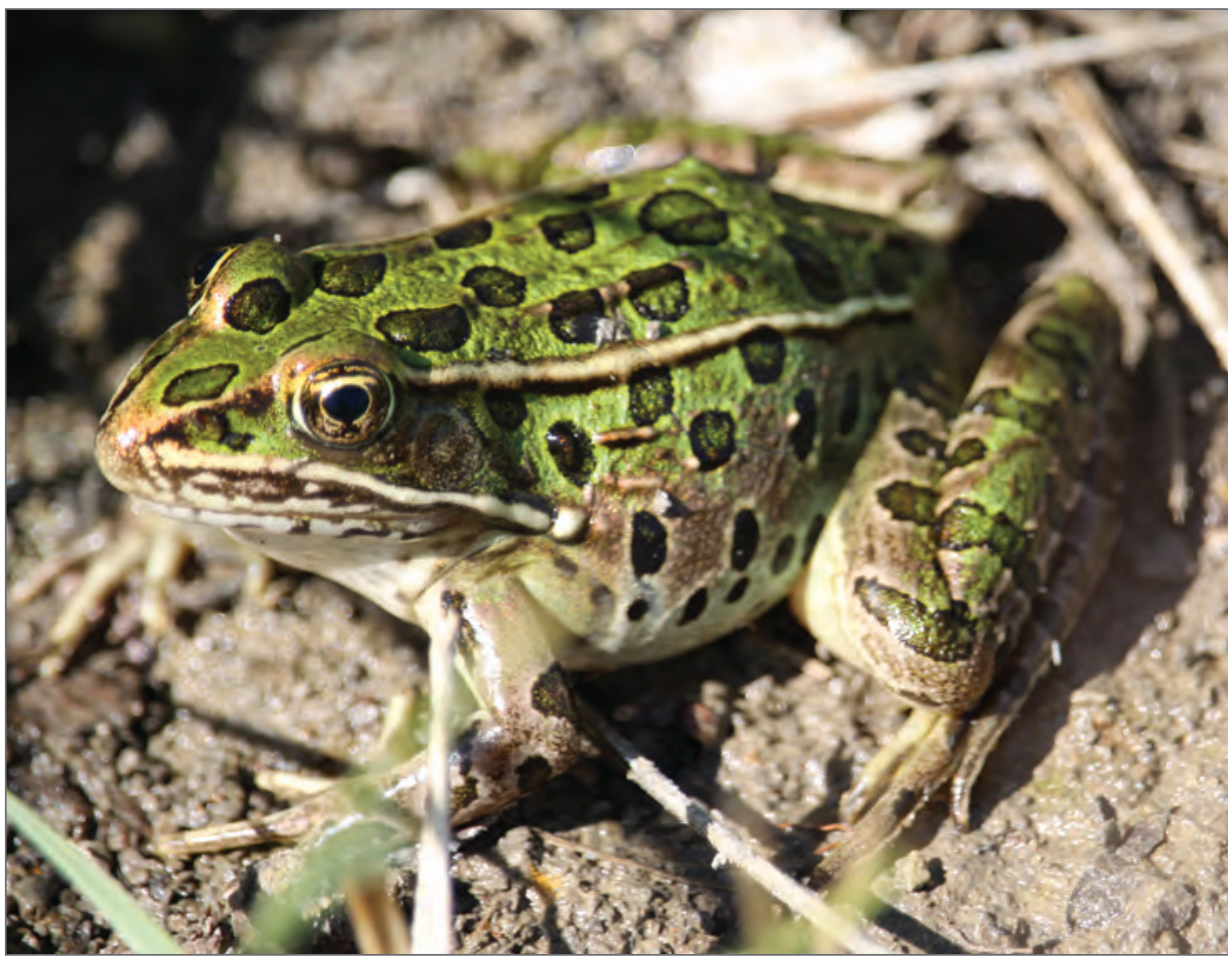

FIGURE 6. Leopard frog, looking well fed? Photo credit: D. Larson frequently prey on adult dragonflies near margins of lentic water bodies, where they employ both stalking and ambush foraging modes. In such habitats ... larger frogs can become dominant predators of Odonata thus reversing the predator-prey relationship in which odonates prevail during the larval stage. ${ }^{15}$

1. Hutchings, G. and D. Halstead. 2011 Dragonflies and damselflies in the hand: an identification guide to boreal forest odonates in Saskatchewan and adjacent regions. Nature Saskatchewan, Special Publication No. 29. 158 pp.

2. Paulson, D. 2009. Dragonflies and damselflies of the west. Princeton Field Guides. Princeton University Press. 535 pp.

3. Walker, E.M. and P.S. Corbet. 1975. The Odonata of Canada and Alaska. Volume 3. University of Toronto Press, Toronto. 307 pp.

4. Hamel, C. and M. Grantham. 2016 Observation on abundant northern leopard frogs at Wargatie Lake, Manitoba. Blue Jay, 74.2:12-13.

5. Corbet, P.S. 1999. Dragonflies. Behavior and Ecology of Odonata. Cornell University Press, Ithaca. 829 pp.

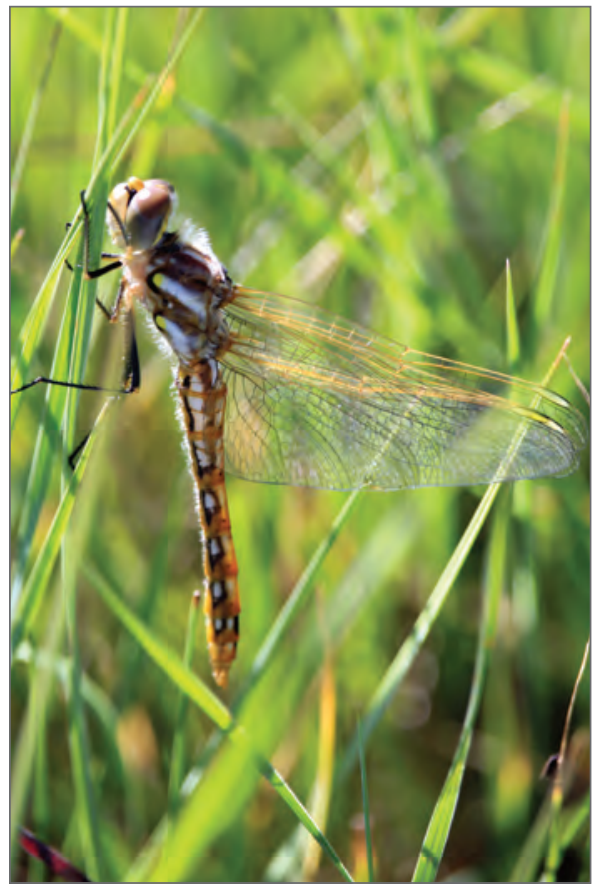

FIGURE 7. Variegated Meadowhawk. The yellow spots on the lower portion of the thorax and the complexly patterned abdomen are unique to immature (teneral) specimens of this species. Photo credit: D. Larson 